\title{
El empresariado en Bogotá: 1830-1930
}

\author{
Entrepreneurship in Bogota: 1830-1930
}

\begin{abstract}
Elber Berdugo C.
Candidato a Doctor en Historia de la Universidad Nacional de Colombia, Sede Bogotá.

Profesor Tiempo Completo Facultad de Ciencias Administrativas y Contables Universidad de La Salle. Profesor Hora Cátedra Escuela de Administración, Contaduría y Mercadeo de la Universidad de Bogotá Jorge Tadeo Lozano.

http://orcid.org/0000-0002-9750-2618

elbere.berdugoc@utadeo.edu.co
\end{abstract}

Fecha de recepción: 11 de julio de 2016 Fecha de aceptación: 25 de julio de 2016

Sugerencia de citación: Berdugo C., E. (2016). El empresariado en Bogotá: 1830-1930. tiempo\&economía, 3(2), 137-141, doi: http://dx.doi.org/10.21789/24222704.1131

La investigación sobre el desarrollo industrial de Bogotá para el periodo 1900-1930 está por hacerse. Hasta el momento no existe un trabajo que dé cuenta del proceso de industrialización en cuanto a sus orígenes y afianzamiento; de los factores que los propiciaron y de los principales agentes propulsores. No se sabe a ciencia cierta cuántas empresas se constituyeron, fecha de creación, características (tipo de sociedad, sectores en que se ubicaron, monto de la inversión, procedencia y tamaño). Tampoco se conoce plenamente la procedencia de los empresarios (extracción social, nacionalidad -de la ciudad, de otras regiones del país, de otros países-). Así mismo, falta profundizar en lo tocante a las actividades económicas de los empresarios, mentalidad (económica, comportamiento ético), y caracterizarlos (innovadores, arriesgados, aprovechadores de oportunidades). Igualmente, no se ha ahondado en lo concerniente al papel desempeñado por el Estado y el capital extranjero en el mismo proceso. Finalmente, falta todavía dilucidar el impacto que ocasionaron algunos acontecimientos externos (Primera 
Guerra Mundial, crisis económica de los comienzos de los veintes y la Gran Depresión) en la actividad industrial de la Capital de la República.

Respecto de los empresarios pioneros de la actividad manufacturera de Bogotá, aun cuando existen algunos trabajos que se destacan -como el de Carlos Dávila (1986): El empresariado colombiano. Una perspectiva histórica, que permite una aproximación a algunos de los empresarios como los Samper, Nemesio Camacho y Pedro A. López, a sus características y al tipo de negocios que desarrollaron; el de Edgar Valero (1999): Empresarios, tecnología y gestión en tres fábricas bogotanas: 1880-1920, en el que se da cuenta de dos empresarios fundadores de dos empresas industriales en la capital: Chocolate Chaves y Bavaria (Enrique Chaves y Leo Kopp)-, hay mucho por hacer.

Con la investigación que se realizó en la Escuela de Administración, Contaduría y Mercadeo de la Universidad Jorge Tadeo Lozano, “La industrialización en Bogotá: 1900-1930", se pretende llenar en parte ese vacío, aportar elementos, generar inquietudes que permitirán a otros investigadores llevar a cabo estudios relacionados con el empresariado de la ciudad. Creemos que la investigación que será publicada por la Universidad aporta a la historia empresarial y, más concretamente, industrial de Bogotá; se constituye en un complemento de las efectuadas sobre la industrialización en otras regiones del país como la de Fernando Botero (1984), La industrialización en Antioquia: 1900-1930; Jorge Conde (1991), La industria en Barranquilla durante el siglo XIX; Adolfo Meisel y Eduardo Posada (1993), ¿Por qué se disipó el dinamismo industrial de Barranquilla?; Sergio Solano (1994), Acumulación de capital e industria. Limitaciones en el desarrollo fabril de Barranquilla: 1900-1934; Milton Zambrano (1998), El desarrollo del empresariado en Barranquilla: 1880-1945; Luis Ordóñez (1999), Industrias y empresarios pioneros: Cali 1910-1945; Amado Guerrero y Maribel Avellaneda (1997), La elite empresarial de Santander (1880-1912); Manuel Rodríguez (1993), El empresario industrial del Viejo Caldas; Albeiro Valencia (1997), El empresario en el antiguo departamento de Caldas (1850-1930); Luisa Giraldo (2001), Modernización e industrialización en el Antiguo Caldas, entre otras, y permitirá una mejor aproximación para explicar el desarrollo industrial del país.

\section{La investigación realizada está compuesta por cuatro partes:}

La primera, “La industrialización en Bogotá: 1830-1930", da cuenta de las razones que indujeron a ciertos sectores de la sociedad a establecer empresas manufactureras en la capital de la República durante el periodo en cuestión y de su extracción social. También se alude al tipo de bienes que produjeron, y a algunas características de esas unidades económicas. Así mismo, se explican las causas del fracaso de muchas de ellas y del éxito de otras. Por otra parte, se analiza el papel desempeñado por el Estado en el surgimiento y desarrollo de la industria en general y la de Bogotá, argumentando que, si bien su apoyo no fue determinante, y en algunos casos poco efectivo, tampoco se puede despreciar el respaldo que brindó a ciertas iniciativas, el cual les ayudó a salir adelante. Finalmente, se hace una alusión tangencial a los aportes del capital extranjero a la industrialización, los cuales no fueron significativos, demasiado influyentes, en dicho proceso en forma directa (inversión en la constitución de empresas manufactureras), aun cuando sí fueron importantes de manera indirecta (empréstitos) al otorgar liquidez al Estado para acometer el desarrollo de las obras públicas y el sistema de transportes, 
lo cual generó economías externas positivas y proveyó al sector privado financiación para el montaje y ensanche de la capacidad instalada que requería.

Para la elaboración de esta parte se hizo una revisión de fuentes notariales (cinco notarías de la ciudad), algunos periódicos y revistas. También se tomaron en consideración trabajos relacionados con la economía, la política, aspectos sociales, la industrialización, las empresas y los empresarios en Bogotá.

La segunda, "Aportes de los empresarios al proceso de modernización en Bogotá: 18701930. El caso de la familia Samper", trata de las realizaciones que llevó a cabo la familia Samper en lo concerniente a los ámbitos material, económico y cultural. Entre los miembros en los que se hizo énfasis están: Miguel Samper Agudelo, quien coadyuvó a la transformación del país y de Bogotá a través de la actividad económica, ya que como empresario desarrolló su casa de comercio de importación y exportación; la fundación de los bancos de Bogotá y Colombia; la creación, junto con otros comerciantes como Salomón Koppel, y Jorge Holguín, de la Cámara de Comercio de Bogotá en 1878, de la que fue miembro de la primera Junta Directiva, y segundo director que reemplazaba eventualmente al gerente Salomón Koppel; su participación en el intento de instalación formal de la Cámara de Comercio de Bogotá en 1898; su papel como precursor de la Empresa de Energía Eléctrica de Bogotá, que sus hijos inauguran en 1900, y de la cual dijo que sin el uso de este servicio no había Revolución Industrial, ni país moderno, ni urbanización; que ella era el antídoto contra el atraso y motor del desarrollo.

Silvestre Samper Agudelo, quien descolló en el comercio y estuvo vinculado a proyectos industriales como la creación de la fábrica de licores y perfumes De los Tres Puentes y una empresa productora de vidrio. A pesar de los fracasos de estas iniciativas, se le abonan su espíritu emprendedor y su afán de coadyuvar a la aclimatación de la actividad manufacturera en Colombia, y concretamente en Bogotá.

También, los hermanos Samper Brush, los cuales dejaron un importante legado en lo económico mediante las sociedades que fundaron y las obras que acometieron, entre las que estuvieron: Samper Brush \& Cía, en 1896, y Cementos Samper, en 1909; la transformación de esta última en 1916 en Compañía de Cemento Samper, que establecieron con el fin de dotar a Bogotá de energía eléctrica, cemento, materiales para la construcción y edificios fabriles e industriales, bancarios, de beneficencia y hospitalarios, religiosos, de vivienda urbana y suburbana, comerciales, de diversión y de renta; casas de comercio, pasajes, teatros y ornato e infraestructura urbana para alcantarillado y acueductos, incluidos diseños de fuentes comunitarias.

Las realizaciones de los hermanos Samper Brush a nivel de la superestructura, que incidieron en el proceso de modernización en la capital de la República como fue el establecimiento en 1914 del Gimnasio Moderno, ideado por la élite de la capital de la República para formar futuros cuadros que dirigieran al país en los campos económico, político y cultural, en cuya constitución desempeñaron un rol trascendental, sobre todo desde el punto de vista económico y administrativo, José María y Tomás.

Igualmente, los aportes de otros integrantes de la familia Samper, como Daniel Samper Ortega, a la educación, con la fundación de la Escuela de Administración Industrial y Comercial del Gimnasio Moderno, culminación del ideal de sus creadores de preparar a sus familiares para que asumieran las riendas del país desde altas posiciones en el Estado y en las empresas 
privadas, y en general, técnicamente a hombres capaces de encauzar el progreso del país. Y al ámbito cultural, al contribuir a la divulgación de la producción literaria nacional, preservar el patrimonio cultural nacional, facilitar el acceso a los libros y estimular la lectura de ellos, elevar el nivel cultural y mejorar la educación de la élite y de la población en general con sus proyectos editoriales como la Selección Samper Ortega, creación de las revistas Santa Fe y Bogotá, Repertorio Selecto y Senderos; la construcción del edificio de la Biblioteca Nacional y reestructuración de esta.

La contribución de otro miembro de la familia Samper, Bernardo Samper Sordo, en el campo de la salud, con la constitución en 1917 del Laboratorio Nacional de Higiene o Samper-Martínez, cuyo objeto fue la producción de vacuna antirrábica y suero antidiftérico y diagnóstico de enfermedades parasitarias y microbianas. Un laboratorio que en su época lo elogiaron científicos de América Latina, Europa y nacionales, lo mismo que el Gobierno y los empresarios colombianos, por sus aportes al desarrollo de la medicina, por su organización. Al respecto, un experto del Viejo continente consideró que no existía en Francia uno de estas dimensiones que lo superara, y en muchas ciudades de Estados Unidos, algunos tan notablemente dotados. Una muestra de ello fueron los premios y los reconocimientos que recibió en el país y en una exposición en Guayaquil (Ecuador).

La tercera parte, "Empresarios en Bogotá", se relaciona con la trayectoria de otros agentes portadores del desarrollo empresarial de la Capital. Ellos son: Leo Kopp, fundador de Bavaria y Fenicia, las dos empresas modernas más importantes en su género en la ciudad y en el país, y de las relevantes del sector manufacturero en general; Plantagenet Moore, quien constituyó la Fábrica de Tubos de Gres Moore, de igual forma, una de las más significativas; Pedro A. López, exportador prominente de café, socio fundador de empresas manufactureras y de servicios públicos; inversionista en bienes raíces y cofundador de uno de los principales bancos del país: el Banco López. Nemesio Camacho, accionista del Banco Central, de ferrocarriles y de empresas industriales y gerente del Tranvía de Bogotá.

La cuarta parte, "Balance historiográfico sobre el empresariado bogotano", da razón de las que se cree son las tendencias que, en términos generales, dominan las investigaciones que hasta el día de hoy se han realizado sobre la actividad empresarial en Bogotá. Una primera la conforman los trabajos que tratan del desarrollo industrial de Bogotá. Otra tendencia la integran aquellos trabajos que de una manera más puntual se centran en el estudio de las empresas bogotanas. Una tercera está compuesta por los trabajos que se propusieron observar a los empresarios localizados en la capital de la República. Y una última de la cual hacen parte trabajos en los que, aunque no tuvieron al empresariado de la capital como propósito específico, aun así, es posible encontrar aspectos relativos a él.

En cada una de las tendencias se exponen los trabajos que se consideran representativos de lo que hasta el momento se ha hecho en relación con la reconstrucción histórica del empresariado bogotano. Se aclara que no se tiene la pretensión de decirlo todo; por lo tanto, lo expuesto debe verse como una simple aproximación. Pero que se le considere como una mera aproximación no puede servir como pretexto para ignorar el hecho de que la intención de este texto es dirigir la atención del mundo académico en general hacia el estudio de este tema para el caso de la ciudad antes mencionada; ciudad que aún espera ser objeto central de las observaciones de este fenómeno desde una perspectiva histórica adecuada. 
El propósito de este balance fue realizar un inventario que oriente desde lo bibliográfico a los interesados en conocer y/o investigar sobre el devenir económico y empresarial en la ciudad. Facilitar por medio de las síntesis realizadas de los trabajos descritos, de sus contenidos, características, fechas de publicación, autores, empresas, empresarios, un mejor acercamiento al tema, y ahorrar tiempo a aquellos que les llame la atención dicho tema. 